\title{
Shifting the Level of Selection in Science
}

\author{
Leo Tiokhin ${ }^{1}$, Karthik Panchanathan ${ }^{2}$, Paul E. Smaldino ${ }^{3}$ and Daniël Lakens ${ }^{1}$ \\ ${ }^{1}$ Human Technology Interaction Group, Eindhoven University of Technology, NL \\ ${ }^{2}$ Department of Anthropology, University of Missouri, USA \\ ${ }^{3}$ Department of Cognitive \& Information Sciences, UC Merced, USA
}

\begin{abstract}
Author Note
Leo Tiokhin https://orcid.org/oooo-ooo1-7333-0383

Karthik Panchanathan https://orcid.org/oooo-0002-5946-6820

Paul Smaldino https://orcid.org/oooo-0oo2-7133-5620

Daniël Lakens https://orcid.org/oooo-00o2-0247-239X
\end{abstract}

All authors benefit both individually and collectively from publishing and disseminating this paper. Leo Tiokhin and Daniël Lakens are co-founders of the company Red Team Market, which provides independent, paid criticism and fraud detection for scientific research. This work was funded by VIDI grant 452-17-013. Leo Tiokhin developed the idea for the paper and was responsible for the final structure. All authors contributed substantially to the conception, drafting, and revision of the work, and agree to be accountable for all aspects of the work. We thank Daniel Hruschka for feedback on an earlier version of this paper.

Correspondence concerning this article should be addressed to: Leo Tiokhin, Human Technology Interaction Group, Eindhoven University of Technology, P.O. Box 513, 560o MB, Eindhoven, the Netherlands. Email: 1.tiokhin@tue.nl 


\begin{abstract}
Criteria for recognizing and rewarding scientists typically focus on individual contributions. This creates a conflict between what is best for scientists' careers and what is best for science. In this paper, we show how principles from the theory of multilevel selection provide a toolkit for modifying incentives to better align individual and collective interests. A core principle is the need to shift the level at which selection operates, from individuals to the groups in which individuals are embedded. This principle is used in several fields to improve collective outcomes, including animal husbandry, professional sports, and professional organizations. Shifting the level of selection has the potential to ameliorate several problems in contemporary science, including accounting for scientists' indirect contributions, reducing individual-level competition, and promoting specialization. We discuss the difficulties associated with changing the level of selection and outline directions for future development in this domain.
\end{abstract}




\section{Shifting the Level of Selection in Science}

The predominant approach to scientific evaluation uses individual-level criteria such as the number of first-authored publications, citations, h-indexes, journal impact factors, and success in funding acquisition (Carpenter et al., 2014; Ioannidis, 2014; McKiernan et al., 2019; Moher et al., 2018; Morales et al., 2021). This evaluation strategy implicitly assumes that identifying and rewarding the most accomplished individuals is the best way to generate scientific knowledge.

Yet scientists contribute to knowledge production in many ways that are not reflected in their individual accomplishments (Moher et al., 2018; Oettl, 2012). Such contributions include being diligent peer reviewers, serving as dedicated mentors, facilitating communication between fields, engaging in replication research, and detecting fraud and statistical errors in published papers. Scientists can also detract from knowledge production in various ways, including being exploitative mentors, sabotaging competitors, engaging in fraud or questionable research practices, and overselling research (Anderson et al., 2007; Chambers, 2017; Ellemers, 2021). Reflecting these concerns, proposals for reform have argued for the need to broaden evaluation criteria (Moher et al., 2018). For example, the Hong Kong Principles for assessing researchers seek to reward behaviors that strengthen research integrity (Moher et al., 2020). Proposals for 'responsible indicators for assessing scientists' (RIAS's) highlight the need to evaluate contributions along dimensions such as peer review, open and reproducible sharing of data and materials, and communication of research via media outlets (Moher et al., 2018). Similarly, the Declaration on Research Assessment (DORA) recommends considering the value from all outputs and outcomes generated by research, using a diversity of metrics (DORA, 2012). Some universities, such as Utrecht University in the Netherlands, have even begun to modify evaluation policies to value a wider range of contributions, such as commitment to collaboration and open science (NWO, n.d.).

Scholars across nations and disciplines increasingly recognize the need to reform scientific evaluation (Moher et al., 2018). Yet, despite many promising ideas, one limitation is that reform proposals rely largely on intuition about which modifications 
will improve the efficiency and reliability of science. Reform proponents acknowledge this point, noting that "the extent to which these [reforms] can be expected to improve the efficiency and reliability of science remains unknown" (Ioannidis, 2014, p.5) and that new evaluation criteria "need to be studied in terms of....the kind of systems needed to implement them...their usefulness in both evaluation and modifying researcher behaviours and the extent to which each may be gamed" (Moher et al., 2018, p. 11). To move beyond intuition-based reform, several scholars have argued that meta-science can productively draw on formal theoretical frameworks from fields that have had a longer history of dealing with related problems (Engel, 2015; Gall et al., 2017; Smaldino, 2019; Tiokhin et al., 2021).

In this paper, we take this approach by illustrating how principles from the evolutionary biological theory of multilevel selection provide conceptual tools for designing scientific reforms. Multilevel-selection theory is used to analyze situations in which individuals are structured into groups, individual behavior affects others' outcomes, and competition occurs at different levels of social organization. Given the presence of these features in academic science, multilevel-selection theory may be particularly relevant for understanding how to modify selection pressures in academic science to improve knowledge generation.

The remainder of this paper proceeds as follows. First, we outline several problems with the reward structure in academia and explain how these arise from the way that individual researchers are evaluated and rewarded. Second, we provide empirical examples of how several fields - animal husbandry, professional sports, and professional organizations - have addressed this class of problems by shifting the level of selection from individuals to groups. Third, we introduce multilevel-selection theory and associated concepts, explain how it is possible to shift the level at which selection operates, and provide principles and potential reforms to address problems in the production of scientific knowledge. Fourth, we discuss the difficulties of modifying the level of selection in practice and provide directions for future development.

\section{A tale of two scientists}


Imagine two scientists, Kotrina and Amber, who have just obtained their PhDs and are entering the job market in psychology. Kotrina has published two empirical papers. She is first author on one, including a publication in a prominent psychology journal, Journal of Experimental Psychology: General. Her papers collectively have 50 citations (with one paper cited 30 times), she has mentored five undergraduate students, and she has obtained a modest research grant. Amber has published six empirical papers. She is first author on three, including three publications in prominent journals, Psychological Science, Journal of Experimental Psychology: General, and PNAS. Amber's papers collectively have over 150 citations (with four papers cited more than 40 times each), she has mentored nine undergraduate students, and she has obtained a major research grant.

Imagine that you were a member of a search committee, and Kotrina and Amber were in the running for your department's final interview spot. Which candidate would you choose?

Given the typical criteria used by departmental selection committees to evaluate scholars (Schimanski \& Alperin, 2018), we expect that most committees would choose Amber. After all, Amber has published more papers, in more prominent journals, with more citations; and Amber has mentored more students and obtained more funding. A good selection committee may realize that focusing on proxy measures such as publication count, citations, and funding can distort science by incentivizing less-rigorous research (Smaldino \& McElreath, 2016). Still, based on standard metrics, it is hard to avoid the conclusion that Amber is doing better work, at a higher rate of productivity, and with more potential for external support. If you needed to select the best individual scientist, Amber would seem like the obvious choice.

\section{Is choosing the "best" scientist so simple?}

Now, suppose that you talk to colleagues and learn more about each candidate before making a decision. You learn that Amber often acts negligently - she does not carefully document her experimental procedures, check her code for bugs, or make her materials available to others. You also learn that Amber engages in questionable research practices (John et al., 2012) to increase the probability that she obtains 
statistically-significant findings. As a consequence, some of Amber's publications likely contain false positives, which will waste the time of scientists who attempt to build on her work. Amber is so driven to succeed that she neglects many prosocial aspects of being an academic - she rarely performs departmental service or helps colleagues when they ask for assistance, and writes short and low-quality peer reviews. To top it off, Amber is a terrible mentor. She barely makes time for students, and when she does, colleagues have seen her exploiting students, stealing their ideas without allocating proper credit, and withdrawing mentorship from students who were struggling. Amber is certainly a productive individual, but she is a poor colleague, peer and community member.

In contrast, you learn that Kotrina typically acts with exceptional diligence - she carefully documents her experimental procedures, double checks her code for bugs, and makes her materials readily accessible to others. Kotrina works hard to avoid questionable research practices and conducts her research slowly and methodically. As a consequence, her publications are more likely to contain true findings and make scientific advances, contributing to the gradual accumulation of knowledge. Kotrina is deeply committed to helping people in her community - she serves on departmental committees, assists colleagues whenever they ask for help, and is a thoughtful and constructive peer reviewer. To top it off, Kotrina is a dedicated mentor. Colleagues mention that Kotrina devotes personal time to helping students become better scholars, credits students for their contributions, and steps up her commitment when students are struggling. Kotrina may not be the most productive individual, but she is a wonderful colleague, peer and community member.

Knowing all of this, would you reconsider your choice? Is it possible to separate Amber and Kotrina's scientific contributions from their effects on the productivity and well-being of colleagues and the broader scientific community?

\section{Typical evaluation criteria ignore indirect effects}

The tale of Kotrina and Amber illustrates two pathways by which scientists contribute to science: directly and indirectly. A 'direct' effect is one in which the causal path goes straight from a scientist's efforts to a measurable scientific outcome. An 
'indirect' effect is one in which the causal path from a scientist's efforts to a measurable scientific outcome goes through other scientists. In other words, indirect contributions are mediated by their effects on other scientists' direct contributions (see Lucas Jr, 1988 for the analogous idea of internal and external benefits in human capital). The causal model in Fig. 1 illustrates these two pathways.

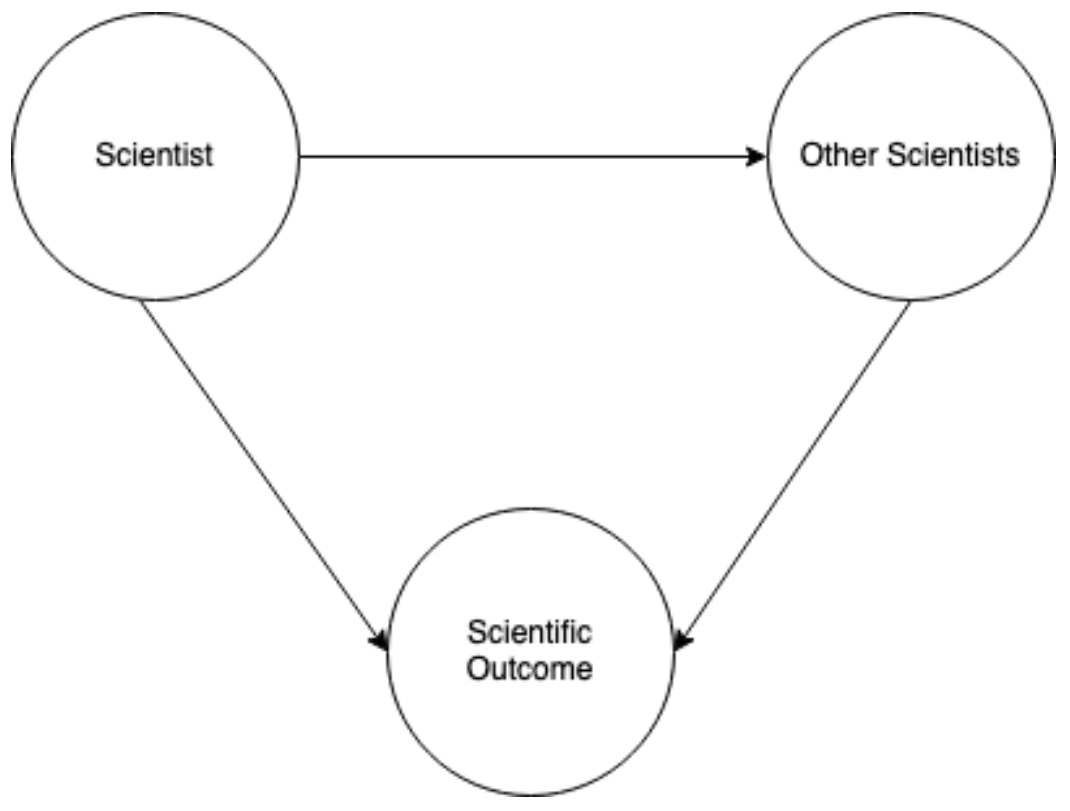

Fig.1. Scientists contribute to any measurable scientific outcome in two ways: directly (scientist $\rightarrow$ scientific outcome) and indirectly (scientist $\rightarrow$ other scientists $\rightarrow$ scientific outcome). A scientist's total causal effect on any scientific outcome is the sum of both direct and indirect effects.

Every scientist can contribute to science via these two pathways. This means that without accounting for both direct and indirect effects, it is impossible to determine a scientist's total contribution to any scientific outcome.

And herein lies the problem: many indirect effects are not accounted for in the metrics used to assess scientists' productivity, such as first-authored publications, h-indexes, and counts of individual citations. Of course, no metric can capture all factors relevant to assessing contributions to scientific knowledge, so is it really that harmful to rely on criteria that primarily measure direct effects? Are there tangible repercussions 
for the efficiency of science, the well-being of scientists, the spread of good scientific practices, or other dimensions that truly matter?

\section{The repercussions of ignoring indirect effects}

We see several reasons why ignoring indirect effects has negative repercussions for science. In the short term, ignoring indirect effects fails to reward scientists who help others and fails to penalize scientists who harm others. In the intermediate-term, ignoring indirect effects increases competition and reduces cooperation between individual scientists. And in the long-term, ignoring indirect effects reduces the incentive for scientists to specialize in roles that are essential for efficient team science.

\section{Ignoring indirect effects fails to reward scientists who help others and fails} to penalize scientists who harm others.

Consider an extreme case in which a scientist generates no direct output, including no first-authored publications. Given current evaluation criteria, such a scientist would struggle to find a research position, obtain grants, and receive awards. Would this be justified?

It depends. If the scientist generates large positive indirect effects, then their total contribution may be sufficient to warrant recognition and rewards, despite the fact that they produce little output themselves. Many of us are familiar with such individuals they are not exceptionally productive, but they lift up their departments, improve their colleagues' productivity, and are a joy to be around.

Next, consider a scientist who generates substantial direct output, including many first-authored publications. Should this scientist be hired, obtain grants, and receive awards?

Again, it depends. If the scientist also generates large positive indirect effects, then a focus on direct output would lead to an underestimate of their total contribution. If, however, the scientist achieves their productivity at others' expense, then ignoring indirect effects would lead to an overestimate of their total contribution. 
Thus, by ignoring indirect effects, current evaluation criteria fail to adequately reward scholars who benefit science by helping others and fail to adequately penalize scholars who detract from science by harming others.

\section{Ignoring indirect effects increases competition and reduces cooperation}

\section{between individual scientists}

Competitive behaviors impose costs on others, whereas cooperative behaviors confer benefits to others (see Table 1 for a taxonomy of social behavior). One consequence of ignoring indirect effects is increased competition and reduced cooperation between scientists. This occurs because indirect effects cause individuals to have a "stake" in each other's outcomes, thereby creating a "shared fate." In evolutionary biology, it is well-established that mechanisms that create a shared fate incentivize individuals to confer benefits to others, reducing individual-level competition and promoting cooperation in many cases (Aktipis et al., 2018; Fletcher \& Doebeli, 2009).

Although competition among individuals can be useful - promoting innovation, increasing effort, and incentivizing scientists to pursue diverse research problems (Balietti et al., 2016; Dechenaux et al., 2015; Strevens, 2003) - competition also has costs. Individual-level competition incentivizes scientists to engage in behaviors that benefit themselves, whereas personally-beneficial behaviors are only a subset of the behaviors that benefit science. For example, the scientific community plausibly benefits from the open sharing of information such as code, materials, and raw data, whereas individual-level competition disincentivizes information sharing to hinder competitors' success (Derex et al., 2014; Mitri et al., 2009). Surveys and focus-group discussions indicate that scientists indeed strategically withhold information in competitive contexts to minimize the probability that others find flaws in their work or succeed in the race for priority of discovery (Anderson et al., 2007; Hagstrom, 1974).

Individual-level competition also incentivizes scientists to be indifferent to their effects on others and even strategically harm others to obtain a competitive advantage. Economic models of public goods demonstrate that without penalties for negative externalities, individuals are more strongly incentivized to engage in selfish behavior that has collectively harmful consequences, such as cutting corners, conducting questionable research practices, or fabricating data (Engel, 2015). Incentives for 
strategic harm occur when a competitor's failure improves the actor's chance of success, such as two labs competing for priority of discovery or two PIs competing for the same grant. Such incentives also occur when an individual can increase their productivity by exploiting others, such as taking advantage of students. Laboratory experiments of stylized peer-review systems demonstrate that competition indeed causes individuals to review competitors' work more negatively (Balietti et al., 2016), and focus-group discussions with scientists at major research universities indicate that scientists engage in many harmful behaviors to succeed in competition, including strategically misreporting research findings to sabotage competitors' progress, delaying peer review of competitors' papers to "beat them to the punch," and lying to and exploiting $\mathrm{PhD}$ students to make progress on projects (Anderson et al., 2007).

Competition and the pursuit of self-interest can make populations worse off, particularly when individuals have competing interests and when competitive success is achieved by investing in traits that diminish individual welfare (Frank, 2012). In academia, selecting scientists based on individual productivity while ignoring indirect effects generates intense individual-level competition, exacerbating the disconnect between the behaviors that lead to successful scientific careers and those that improve the quality of the scientific literature and the well-being of scientists (Munafò et al., 2017; Nosek et al., 2012; Smaldino \& McElreath, 2016).

Ignoring indirect effects reduces the incentive to specialize in roles that are essential for efficient team science.

The widespread reliance on metrics that target direct individual contributions creates an additional problem: scientists have few incentives to specialize in roles in which they primarily assist others, even though such roles are essential for efficient team science. Team science benefits from specialists whose primary role is to generate positive indirect effects for other team members (e.g., dedicated statisticians, programmers, or facilitators of communication) (Fleming, 2021; Forscher et al., 2020; Wuchty et al., 2007). More generally, groups benefit from diverse sets of specialists because individuals who specialize can achieve mastery that surpasses that of generalists: teams of specialists with complementary skills regularly outperform teams of generalists with overlapping skills, even if the generalists are top performers (Page, 
2007). Over time, selection for efficient groups leads to cooperative entities that are more than the sum of individual parts. Such entities involve efficient divisions of labor, systems of communication to coordinate cooperation, mechanisms to suppress competition, and entities that have a shared fate and can no longer function independently (e.g., genes to genomes, cells to multicellular organisms, multicellular organisms to colonies) (Frank, 2003; Szathmáry \& Smith, 1995; West et al., 2015).

In contrast, focusing on direct individual contributions pushes scientists away from roles that primarily help fellow team members and towards roles that receive individual recognition, such as being a team leader or PI. This leads to the situation lamented by Kurt Vonnegut, in which "...everyone wants to build and nobody wants to do maintenance" (Vonnegut, 1997, p. 167).

\section{Lessons from animal husbandry, professional sports, and professional organizations}

How can indirect effects be accounted for to better align the interests of individual scientists with broader scientific goals? To address this question, we draw on insights from three fields - animal husbandry, professional sports, and professional organizations - that have long dealt with similar challenges. Each of these fields recognize the need to move away from individual-level evaluation to improve group-level outcomes, and all of them make use of a shared principle for doing so: shifting the level of selection, away from individuals and towards the larger groups in which individuals are embedded.

\section{Animal husbandry}

Farmers aim to implement a breeding strategy that maximizes profits. In poultry, this amounts to maximizing hens' lifetime egg production. One sensible approach might be to select the most productive individual chickens to reproduce. The reality, however, is not so simple. The causal pathways that affect individual hens' egg production are complicated because each hen's productivity is influenced by the behavior of other hens in their social environment. It turns out that most productive hens in a coop are also the nastiest hens, feather-pecking and cannibalizing their coop mates. Because individual hens who are most productive are those that harm others, selectively breeding the most 
productive hens can actually lead to lower overall egg production (Muir, 2005; Wade et al., 2010).

From an economic perspective, feather-pecking and cannibalism are problems when they cut into profits (El-Lethey et al., 2000). From an animal welfare perspective, they are tragedies. Yet, breeders have developed a strategy to address these problems: instead of selecting the most productive individuals, breeders can select the most productive groups, such that all hens in the most productive coops are selected to reproduce. Such a selection regime implicitly accounts for hens' indirect effects on group members (Wade et al., 2010). In one application of this approach to poultry, mortality dropped from $68 \%$ to $9 \%$ in just a few generations, and laying increased from 91 to 237 eggs (Muir, 1996).

\section{Professional sports}

Sports managers want their teams to win. To accomplish this goal, managers must evaluate and preferentially select players who make the largest positive impacts on team performance. Selecting players with impressive individual performance metrics, such as goals scored, may seem like the obvious approach. However, as with chickens who lay many eggs, players with impressive individual metrics are not always the ones who have maximally positive impacts on their teams. For instance, a soccer player who always shoots and never passes increases their chance of scoring goals, but reduces their team's probability of winning games relative to a player who passes when others are in a better position to score. Thus, evaluations of professional athletes rely not only on metrics of individual performance, but also on metrics that capture indirect effects (Berri \& Bradbury, 2010; Duch et al., 2010).

In the National Hockey League (NHL), the "plus-minus" statistic provides information about a team's performance when a player is both on and off the ice, thereby helping managers decide which players put their teams in positions to win. Other statistics measure goal-scoring attempts, shot quality, shots blocked, whether success was due to luck, and attempt to control for context (such as "garbage time" play or differences between rinks) (Nandakumar \& Jensen, 2019). In Major League Baseball (MLB), managers and fans once relied on individual statistics such as batting average and home runs. However, such metrics did not measure many indirect effects and were 
poor predictors of team wins. Currently, managers use metrics that capture both direct individual performance (such as slugging percentage and weighted on-base percentage) and indirect contributions to team performance (such as plus-minus, weighted runs created, defensive runs saved and value over replacement player) (Beneventano et al., 2012). It is also recognized that many contributions are difficult to measure with metrics (such as leadership and improving team morale) because of the complicated causal chains between players' actions and team performance (Silver, 2012).

\section{Professional organizations}

Like sports teams, organizations seek to hire and invest in workers who improve organizational productivity. One approach is to hire 'stars', individuals who are exceptionally productive and innovative (Ernst et al., 2000; Groysberg et al., 2008). While such an approach works in some cases, a focus on productive individuals can also harm organizational outcomes. The problem arises because metrics of individual productivity rarely capture the indirect ways that individuals impact organizations (DeLong \& Vijayaraghavan, 2003; Housman \& Minor, 2015; Pentland, 2012). For example, some employees are "charismatic connectors" who facilitate communication among team members (Pentland, 2012). Others score high on measures of network centrality, having large, dense, or far-reaching networks of collaborators (Grigoriou \& Rothaermel, 2014). Although such individuals may not be individually productive, they can help an organization to achieve its goals by creating more productive interactions among team members or by promoting innovation by recombining knowledge from disparate sources.

Organizations that overemphasize the direct contributions of 'stars' also run the risk of overlooking the ways in which stars indirectly harm organizations. Stars can constrain the emergence of new leaders, both because organizations allocate disproportional resources to support the star's research program and because stars have incentives to prevent other employees from advancing to high-status roles (Kehoe \& Tzabbar, 2015). Stars can dominate discussions and champion their own ideas, whereas better solutions would have arisen had a diverse set of individuals contributed in a more democratic system (Page, 2006; Woolley et al., 2010). A further problem is that of 'star' employees who are individually productive but harm fellow employees and corrupt 
organizational culture (so called "toxic workers") (Housman \& Minor, 2015). Toxic workers are selfish, overconfident, engage in harassment, funnel organizational resources towards personal goals, and act unethically in various other ways. One analysis of productivity among workers at a company building and deploying job-testing software estimated that removing productive-but-toxic workers would increase firm profits even more so than hiring star employees (Housman \& Minor, 2015).

To mitigate such problems, organizations make use of group-level incentives (Suff et al., 2008). In the simplest form, organizations place employees into teams with shared goals (Hansen, 1997). Many organizations also create explicit incentive schemes in which employee payoffs are tied to the success of the organization, including profit sharing (salaries depend on company profits) and providing employees with stock options or allowing employees to buy company stock at discounted prices. Another approach is to offer team-based performance incentives, in which employees are rewarded when their team meets specific standards or output targets (increasing sales, efficiency, or successfully accomplishing a project). Such group-level incentives encourage employees to identify more with their organization, aligning the interests of individuals and the larger group in which they are embedded (Pendleton et al., 1998).

\section{Multilevel-selection theory}

Animal husbandry, professional sports, and professional organizations illustrate an overarching lesson. If the goal is to foster group productivity, then it is essential to account for the indirect effects of individuals' behaviors on other group members by shifting the level of selection from individuals to groups. Shifting selection to the level of groups creates incentives for within-group cooperation and reduces incentives for within-group competition. This occurs because group-level selection creates a shared fate among group members, wherein each individual's success becomes tied to the success of the group. Shifting the level of selection from individuals to groups favors the spread of behaviors, norms, and institutions that promote group success, regardless of whether individuals consciously understand the underlying causal processes (Boyd \& Richerson 2002; Derex et al. 2019). 
More formally, cooperation and competition are examples of what biologists call 'social' behaviors - behaviors that have fitness consequences for both the actor and other individuals (West et al. 2007). Social behaviors can have either positive or negative effects on an actor and on other individuals (Table 1). We label behaviors in which actors confer benefits on others as 'cooperative' and behaviors in which actors impose costs on others as 'competitive'. Among the competitive behaviors, 'selfish' behaviors benefit the actor and 'spiteful' behaviors harm the actor. Among the cooperative behaviors, 'mutually beneficial' behaviors benefit the actor and 'altruistic' behaviors harm the actor.

\begin{tabular}{|c|c|c|}
\hline & \multicolumn{2}{|c|}{ Effect on others } \\
\hline Effect on the actor & Positive (cooperative) & Negative (competitive) \\
\hline Positive & Mutually Beneficial & Selfish \\
\hline Negative & Altruistic & Spiteful \\
\hline
\end{tabular}

Table 1. A taxonomy of social behavior.

Biologists use multilevel-selection theory to study systems that are hierarchically organized (such as genes grouped into cells, cells grouped into individual organisms, individual organisms grouped into groups) such that evolution can simultaneously operate at multiple hierarchical levels (Okasha, 2006; Wilson, 1975). A key insight is that strong selection between groups can favor the evolution of cooperation and suppression of competition within groups, because cooperative groups can outcompete selfish groups. Two factors determine the dominant level at which selection operates: the relative intensity of competition within versus between groups, and the extent of variation in social behaviors within and between groups (Okasha 2006). These insights have been formalized mathematically in a framework known as the Price Equation (for additional information and derivation, see Kerr \& Godfrey-Smith, 2002; McElreath \& Boyd, 2008; Okasha, 2006).

When individuals fiercely compete with members of their own group, they are incentivized to act selfishly and disincentivized from acting altruistically, because individual success depends largely on outcompeting fellow group members. However, 
when competition is weaker within groups and stronger between groups, selection at the group level dominates. Individuals then have few incentives to engage in selfish behavior because personal success does not depend as much on outcompeting fellow group members. At the extreme, when there is no competition within groups, the only way that individuals can improve their personal success is by improving the success of their group (Frank, 2003). High between-group competition thus creates a situation of shared fate for group members: every individual's success becomes dependent on the group's success in inter-group competition, incentivizing less competition and more cooperation with fellow group members.

\section{Shifting the level of selection in practice}

Multilevel-selection theory and the taxonomy of social behavior provide conceptual tools for developing potential scientific reforms and reasoning about their consequences. Given the early stages of our understanding of how group structure affects the evolution of scientific practices, recommendations for specific policy changes are not yet warranted (IJzerman et al., 2020). Shifting the level of selection in practice will require dealing with substantial challenges, including identifying the relevant level of hierarchical organization (ranging from research labs to scientific fields to countries), desirable outcomes to incentivize (such as theoretical progress or solutions to societal problems), the mechanism by which selection is implemented (such as grant allocation or criteria for hiring and promotion), and a range of additional complications (see Limitations). In this section, we speculate about potential reforms to shift the level of selection upwards, with the goal of inspiring additional research in this area.

One subset of reforms might involve shifting scientific evaluation to more strongly consider group outcomes. Just as companies provide employees with stock options and bonuses based on company performance, promotion or rewards could be made partially contingent on the performance of groups in which scientists are embedded, such as departments. Other reforms could entail funding permanent positions for individuals whose primary role is not to produce research, but rather to help others improve their research output. Such positions may include departmental 
statisticians, technicians, data managers, theoretical modelers, and individuals who facilitate communication among scientists.

Other approaches could involve developing metrics to more formally account for indirect effects. Given current unsystematic approaches to evaluating indirect effects (letters of recommendation to assess collegiality, informally weighing contributions to papers based on authorship order) there is substantial room for innovation in this area. Progress has already been made in certain domains, such as the development of the Contributor Roles Taxonomy (CRediT) (McNutt et al., 2018) and citation-based algorithms (Shen \& Barabasi, 2014) to determine collective credit allocation in multi-authored papers. Metrics of network centrality may be useful for determining which scientists have large, dense, or far-reaching networks of collaborators, or have the potential to fill structural holes (Burt, 2004; Li et al., 2013). This approach has shown promise in other fields (Duch et al., 2010), but its application requires grappling with the challenge of multiplex networks, characterized by multiple interacting network layers across various domains of academic life (Lee et al., 2015). A heretofore neglected domain is that of metrics to capture how scientists harm scientific progress (e.g., generating unreliable results by engaging in questionable research practices).

Additional reforms to shift the level of selection could involve creating competitions that incentivize larger-scale cooperation. Corporations such as Netflix have successfully created such competitions by offering financial prizes for improvements to their movie-recommendation algorithm ("Netflix Prize," 2021). Similarly, science funders could create competitions to funnel scientists towards critical outstanding problems. Such an approach is already used by the Clay Mathematics Institute, which offers 1 million USD for correct solutions to unsolved problems in mathematics ("Millennium Prize Problems," 2021). Funders can also encourage antagonistic collaborations between competing teams, with the goal of reconciling conflicting findings and developing theoretical consensus. Such an approach was recently implemented by the Templeton Foundation to fund structured adversarial collaborations to test competing theories in the research area of consciousness (Accelerating Research on Consciousness, n.d.).

A final approach could focus on suppressing competition within groups, as selection is shifted upwards by mechanisms that reduce within-group competition 
(Frank, 2003), thereby increasing the relative variation between groups. One possibility for doing so is to develop institutions that produce more equal outcomes, such as departments in which individual faculty members' resources are partially redistributed among fellow faculty or in which there are limits on the number of graduate students that can work with a PI. Another leveling mechanism is randomization. Randomization places individuals behind a "veil of ignorance" about their future outcomes (Rawls, 1971), such that each individual can only increase their chances of success by increasing the average success of the group. As with redistribution, randomization reduces inequality in expected outcomes within groups. Unlike redistribution, randomization acts like a lottery: in any specific instance, one individual receives a disproportionately large payoff. As a consequence, randomization is preferable in situations of increasing marginal returns, whereas redistribution is preferable in situations of diminishing marginal returns (Nettle et al., 2011). In the context of grant funding, formal models demonstrate that randomization can both increase scientific efficiency and decrease the individual-level competition that selects for reduced rigor (Gross \& Bergstrom, 2019; Smaldino et al., 2019). Creating a veil of ignorance by using blinded analyses has also been proposed as a way to prevent questionable research practices (Dutilh et al., 2019).

Another way to suppress competition is to make it easier for individuals to police group-detrimental behaviors. One approach is to fund independent entities to evaluate research quality or conduct audits of researchers (Barnett et al., 2018). Examples include the NAS Strategic Council for Research Excellence, Integrity, and Trust in the U.S. (McNutt et al., 2021) and random audits of procedures for collecting data, research methods, reporting misconduct (Science Committee, n.d.; Van Noorden, 2014). Other possibilities include providing grants and permanent positions for individuals who engage in scientific criticism, ranging from rigorous peer-review to fraud detection to "red teams" of independent critics (Lakens, 2020; Vazire \& Holcombe, 2020).

\section{Limitations}

There are limitations to applying concepts from multilevel-selection theory to scientific reform. One concern is the possibility of gaming. Campbell's Law states that "the more any quantitative social indicator is used for social decision-making, the more 
subject it will be to corruption pressures and the more apt it will be to distort and corrupt the social processes it is intended to monitor" (Campbell, 1979). Gaming is a problem regardless of the level at which selection operates and is an issue in many sectors (Larkin, 2014). However, gaming is particularly worrisome in instances when there is a weak link between the target of selection, such as a metric, and the desired outcome, such as theoretical progress. Gaming has been less of a concern in domains where multilevel-selection theory has previously been applied, such as breeding hens for higher egg yield, because selection operated directly on the parameter that was desirable to maximize.

Although we have focused on the benefits of large-scale cooperation, not all science will benefit from such an approach. Similarly, not every scientist will make a larger scientific contribution by engaging in more collaborative research. Although some tasks are insurmountable without large-scale cooperative teams (e.g., CERN's efforts to build the Large Hadron Collider involved a collaboration between over 10,000 scientists across 100 countries), others benefit from smaller-scale efforts. A recent large-scale analysis of patents, software projects, and academic publications between 1954 and 2014 found that large research teams tended to develop existing ideas, whereas small teams were more likely to generate "disruptive" ideas that constituted scientific and technological breakthroughs (Wu et al., 2019). Science policies must find ways to promote larger-scale cooperation while also valuing smaller-scale research and rewarding a diversity of team sizes.

The conditions in which shifting selection upwards will benefit science and improve welfare require further study. Larger-scale cooperative groups can more effectively harm competing groups (Zefferman \& Mathew, 2015). Further, although group-level selection can improve welfare, it may also reduce it: despotic political regimes can rise to power by promoting institutions that allow them to dominate and assimilate more democratic neighboring polities (Makowsky \& Smaldino, 2016; Turchin, 2016). Reforms to shift selection upwards should thus be supplemented by regulations to prevent welfare-reducing outcomes, as has been done in other competitive domains, such as mandates for helmet use in professional hockey (Frank, 2012). 
A final issue is the potential to crowd out moral incentives with external rewards for performance (Bowles, 2016). Much of science is characterized by group-beneficial behaviors that generate no financial rewards but are engaged in due to reputational concerns, reciprocal relationships with colleagues, or embodiment of prosocial norms (Merton, 1973). Such behaviors include peer-review, providing feedback on colleagues' manuscripts, mentoring students, writing letters of recommendation, and giving talks. Because adding external rewards can reduce the weight placed on internal rewards, this can result in even lower levels of the rewarded behavior (Gneezy \& Rustichini, 2000). The extent of crowding out is difficult to anticipate, and lab experiments and smaller-scale pilot interventions are key tools for understanding its potential consequences.

\section{Conclusion}

Scientists are evaluated based on their individual performance. Such evaluation criteria create a disconnect between what is best for scientists' careers and what is best for science. Problems generated by a focus on direct individual contributions include failing to account for the indirect ways that scientists contribute to science, incentivizing selfishness and disincentivizing cooperation, intensifying competition between scientists, and hindering specialization and the emergence of large-scale cooperative scientific teams. Multilevel-selection theory provides a framework for understanding how to address these problems and has been productively applied in several fields to improve group outcomes. The key principle is to account for indirect effects by changing the level of selection from the level of individuals to the level of groups. Shifting selection to the group level creates a shared fate among group members, fostering cooperation and hindering competition within groups. Shifting the level of selection is far from simple and its practical application requires further study. Yet, given its theoretical promise and empirical track record, shifting the level of selection should be considered as a potential overarching principle for structuring scientific reform. 


\section{References}

Accelerating Research on Consciousness. (n.d.). Retrieved October 20, 2021, from https://www.templetonworldcharity.org/our-priorities/accelerating-research-consciousnes S

Aktipis, A., Cronk, L., Alcock, J., Ayers, J. D., Baciu, C., Balliet, D., Boddy, A. M., Curry, O. S., Krems, J. A., \& Muñoz, A. (2018). Understanding cooperation through fitness interdependence. Nature Human Behaviour, 2(7), 429.

Anderson, M. S., Ronning, E. A., De Vries, R., \& Martinson, B. C. (2007). The perverse effects of competition on scientists' work and relationships. Science and Engineering Ethics, 13(4), 437-461.

Balietti, S., Goldstone, R. L., \& Helbing, D. (2016). Peer review and competition in the Art Exhibition Game. Proceedings of the National Academy of Sciences, 201603723.

Barnett, A. G., Zardo, P., \& Graves, N. (2018). Randomly auditing research labs could be an affordable way to improve research quality: A simulation study. PLOS ONE, 13(4), e0195613. https://doi.org/10.1371/journal.pone.0195613

Beneventano, P., Berger, P. D., \& Weinberg, B. D. (2012). Predicting run production and run prevention in baseball: The impact of Sabermetrics. Int J Bus Humanit Technol, 2(4), 67-75.

Berri, D. J., \& Bradbury, J. C. (2010). Working in the land of the metricians. Journal of Sports Economics, 11(1), 29-47.

Bowles, S. (2016). The moral economy: Why good incentives are no substitute for good citizens. Yale University Press.

Burt, R. S. (2004). Structural holes and good ideas. American Journal of Sociology, 110(2), 
349-399.

Campbell, D. T. (1979). Assessing the impact of planned social change. Evaluation and Program Planning, 2(1), 67-90.

Carpenter, C. R., Cone, D. C., \& Sarli, C. C. (2014). Using publication metrics to highlight academic productivity and research impact. Academic Emergency Medicine, 21(10), $1160-1172$.

Chambers, C. (2017). The seven deadly sins of psychology: A manifesto for reforming the culture of scientific practice. Princeton University Press.

Dechenaux, E., Kovenock, D., \& Sheremeta, R. M. (2015). A survey of experimental research on contests, all-pay auctions and tournaments. Experimental Economics, 18(4), 609-669.

DeLong, T. J., \& Vijayaraghavan, V. (2003). Let's hear it for B players. Harvard Business Review, 81(6), 96-102, 137.

Derex, M., Godelle, B., \& Raymond, M. (2014). How does competition affect the transmission of information? Evolution and Human Behavior, 35(2), 89-95.

DORA. (2012). San Francisco declaration on research assessment. https://sfdora.org/

Duch, J., Waitzman, J. S., \& Amaral, L. A. N. (2010). Quantifying the Performance of Individual Players in a Team Activity. PLOS ONE, 5(6), e10937. https://doi.org/10.1371/journal.pone.0010937

Dutilh, G., Sarafoglou, A., \& Wagenmakers, E.-J. (2019). Flexible yet fair: Blinding analyses in experimental psychology. Synthese. https://doi.org/10.1007/s11229-019-02456-7

Ellemers, N. (2021). Science as collaborative knowledge generation. British Journal of Social Psychology, 60(1), 1-28. https://doi.org/10.1111/bjso.12430

El-Lethey, H., Aerni, V., Jungi, T. W., \& Wechsler, B. (2000). Stress and feather pecking in laying hens in relation to housing conditions. British Poultry Science, 41(1), 22-28.

Engel, C. (2015). Scientific disintegrity as a public bad. Perspectives on Psychological Science, 
10(3), 361-379.

Ernst, H., Leptien, C., \& Vitt, J. (2000). Inventors are not alike: The distribution of patenting output among industrial R\&D personnel. IEEE Transactions on Engineering Management, 47(2), 184-199.

Fleming, N. (2021). The authorship rows that sour scientific collaborations. Nature, 594(7863), 459-462. https://doi.org/10.1038/d41586-021-01574-y

Fletcher, J. A., \& Doebeli, M. (2009). A simple and general explanation for the evolution of altruism. Proceedings of the Royal Society B: Biological Sciences, 276(1654), 13-19. https://doi.org/10.1098/rspb.2008.0829

Forscher, P. S., Wagenmakers, E.-J., DeBruine, L., Coles, N., Silan, M. A., \& IJzerman, H. (2020). A manifesto for team science.

Frank, R. H. (2012). The Darwin economy: Liberty, competition, and the common good. Princeton University Press.

Frank, S. A. (2003). Repression of Competition and the Evolution of Cooperation. Evolution, 57(4), 693-705. https://doi.org/10.1111/j.0014-3820.2003.tb00283.x

Gall, T., loannidis, J. P., \& Maniadis, Z. (2017). The credibility crisis in research: Can economics tools help? PLoS Biology, 15(4).

Gneezy, U., \& Rustichini, A. (2000). A fine is a price. The Journal of Legal Studies, 29(1), 1-17.

Grigoriou, K., \& Rothaermel, F. T. (2014). Structural microfoundations of innovation: The role of relational stars. Journal of Management, 40(2), 586-615.

Gross, K., \& Bergstrom, C. T. (2019). Contest models highlight inherent inefficiencies of scientific funding competitions. PLoS Biology, 17(1), e3000065.

Groysberg, B., Lee, L.-E., \& Nanda, A. (2008). Can they take it with them? The portability of star knowledge workers' performance. Management Science, 54(7), 1213-1230.

Hagstrom, W. O. (1974). Competition in science. American Sociological Review, 1-18. Hansen, D. G. (1997). Worker performance and group incentives: A case study. ILR Review, 
51(1), 37-49.

Housman, M., \& Minor, D. (2015). Toxic workers. Harvard Business School Strategy Unit Working Paper, 16-057.

IJzerman, H., Lewis, N. A., Przybylski, A. K., Weinstein, N., DeBruine, L., Ritchie, S. J., Vazire, S., Forscher, P. S., Morey, R. D., \& Ivory, J. D. (2020). Use caution when applying behavioural science to policy. Nature Human Behaviour, 4(11), 1092-1094.

loannidis, J. P. (2014). How to make more published research true. PLoS Medicine, 11(10), e1001747.

John, L. K., Loewenstein, G., \& Prelec, D. (2012). Measuring the prevalence of questionable research practices with incentives for truth telling. Psychological Science, 23(5), $524-532$.

Kehoe, R. R., \& Tzabbar, D. (2015). Lighting the way or stealing the shine? An examination of the duality in star scientists' effects on firm innovative performance. Strategic Management Journal, 36(5), 709-727.

Kerr, B., \& Godfrey-Smith, P. (2002). Individualist and multi-level perspectives on selection in structured populations. Biology and Philosophy, 17(4), 477-517.

Lakens, D. (2020). Pandemic researchers-recruit your own best critics. Nature, 581(7807), 121. Larkin, I. (2014). The cost of high-powered incentives: Employee gaming in enterprise software sales. Journal of Labor Economics, 32(2), 199-227.

Lee, K.-M., Min, B., \& Goh, K.-I. (2015). Towards real-world complexity: An introduction to multiplex networks. The European Physical Journal B, 88(2), 1-20.

Li, E. Y., Liao, C. H., \& Yen, H. R. (2013). Co-authorship networks and research impact: A social capital perspective. Research Policy, 42(9), 1515-1530.

Lucas Jr, R. E. (1988). On the mechanics of economic development. Journal of Monetary Economics, 22(1), 3-42.

Makowsky, M. D., \& Smaldino, P. E. (2016). The evolution of power and the divergence of 
cooperative norms. Journal of Economic Behavior \& Organization, 126, 75-88.

McElreath, R., \& Boyd, R. (2008). Mathematical models of social evolution: A guide for the perplexed. University of Chicago Press.

McKiernan, E. C., Schimanski, L. A., Nieves, C. M., Matthias, L., Niles, M. T., \& Alperin, J. P. (2019). Meta-research: Use of the journal impact factor in academic review, promotion, and tenure evaluations. ELife, 8, e47338.

McNutt, M., France A. Córdova, \& Allison, D. B. (2021). The Strategic Council for Research Excellence, Integrity, and Trust. Proceedings of the National Academy of Sciences, 118(41). https://doi.org/10.1073/pnas.2116647118

McNutt, M. K., Bradford, M., Drazen, J. M., Hanson, B., Howard, B., Jamieson, K. H., Kiermer, V., Marcus, E., Pope, B. K., \& Schekman, R. (2018). Transparency in authors' contributions and responsibilities to promote integrity in scientific publication. Proceedings of the National Academy of Sciences, 115(11), 2557-2560.

Merton, R. K. (1973). The sociology of science: Theoretical and empirical investigations. University of Chicago press.

Millennium Prize Problems. (2021). In Wikipedia. https://en.wikipedia.org/w/index.php?title=Millennium_Prize_Problems\&oldid=10481426 13

Mitri, S., Floreano, D., \& Keller, L. (2009). The evolution of information suppression in communicating robots with conflicting interests. Proceedings of the National Academy of Sciences, 106(37), 15786-15790. https://doi.org/10.1073/pnas.0903152106

Moher, D., Bouter, L., Kleinert, S., Glasziou, P., Sham, M. H., Barbour, V., Coriat, A.-M., Foeger, N., \& Dirnagl, U. (2020). The Hong Kong Principles for assessing researchers: Fostering research integrity. PLOS Biology, 18(7), e3000737. https://doi.org/10.1371/journal.pbio.3000737

Moher, D., Naudet, F., Cristea, I. A., Miedema, F., Ioannidis, J. P. A., \& Goodman, S. N. (2018). 
Assessing scientists for hiring, promotion, and tenure. PLOS Biology, 16(3), e2004089. https://doi.org/10.1371/journal.pbio.2004089

Morales, E., McKiernan, E., Niles, M. T., Schimanski, L., \& Alperin, J. P. (2021). How faculty define quality, prestige, and impact in research. BioRxiv, 2021.04.14.439880. https://doi.org/10.1101/2021.04.14.439880

Muir, W. M. (1996). Group selection for adaptation to multiple-hen cages: Selection program and direct responses. Poultry Science, 75(4), 447-458.

Muir, W. M. (2005). Incorporation of competitive effects in forest tree or animal breeding programs. Genetics, 170(3), 1247-1259.

Munafò, M. R., Nosek, B. A., Bishop, D. V., Button, K. S., Chambers, C. D., Du Sert, N. P., Simonsohn, U., Wagenmakers, E.-J., Ware, J. J., \& loannidis, J. P. (2017). A manifesto for reproducible science. Nature Human Behaviour, 1(1), 1-9.

Nandakumar, N., \& Jensen, S. T. (2019). Historical perspectives and current directions in hockey analytics. Annual Review of Statistics and Its Application, 6, 19-36.

Netflix Prize. (2021). In Wikipedia.

https://en.wikipedia.org/w/index.php?title=Netflix_Prize\&oldid=1049141816

Nettle, D., Panchanathan, K., Rai, T. S., \& Fiske, A. P. (2011). The evolution of giving, sharing, and lotteries. Current Anthropology, 52(5), 747-756.

Nosek, B. A., Spies, J. R., \& Motyl, M. (2012). Scientific utopia: II. Restructuring incentives and practices to promote truth over publishability. Perspectives on Psychological Science, 7(6), 615-631.

NWO. (n.d.). Position paper "Room for everyone's talent." Retrieved April 17, 2021, from https://www.nwo.nl/en/position-paper-room-everyones-talent

Oettl, A. (2012). Reconceptualizing stars: Scientist helpfulness and peer performance. Management Science, 58(6), 1122-1140.

Okasha, S. (2006). Evolution and the levels of selection. Oxford University Press. 
Page, S. (2006). The difference. How the Power of Diversity Creates Better Groups, Firms.

Pendleton, A., Wilson, N., \& Wright, M. (1998). The perception and effects of share ownership: Empirical evidence from employee buy-outs. British Journal of Industrial Relations, 36(1), 99-123.

Pentland, A. "Sandy." (2012, April 1). The New Science of Building Great Teams. Harvard Business Review. https://hbr.org/2012/04/the-new-science-of-building-great-teams

Rawls, J. (1971). A theory of justice. Harvard university press.

Schimanski, L. A., \& Alperin, J. P. (2018). The evaluation of scholarship in academic promotion and tenure processes: Past, present, and future (7:1605). F1000Research. https://doi.org/10.12688/f1000research.16493.1

Shen, H.-W., \& Barabasi, A.-L. (2014). Collective credit allocation in science. Proceedings of the National Academy of Sciences, 111(34), 12325-12330. https://doi.org/10.1073/pnas.1401992111

Silver, N. (2012). The signal and the noise: The art and science of prediction. Penguin UK.

Smaldino, P. (2019). Better methods can't make up for mediocre theory. Nature, 575(7781), 9-9. https://doi.org/10.1038/d41586-019-03350-5

Smaldino, P. E., \& McElreath, R. (2016). The natural selection of bad science. Royal Society Open Science, 3(9), 160384.

Smaldino, P. E., Turner, M. A., \& Contreras Kallens, P. A. (2019). Open science and modified funding lotteries can impede the natural selection of bad science. Royal Society Open Science, 6(7), 190194. https://doi.org/10.1098/rsos.190194

Strevens, M. (2003). The role of the priority rule in science. The Journal of Philosophy, 100(2), $55-79$.

Suff, P., Reilly, P., \& Cox, A. (2008). All Together Now Group reward strategies.

Szathmáry, E., \& Smith, J. M. (1995). The major evolutionary transitions. Nature, 374(6519), 227-232. 
Tilburg University. (n.d.). Science Committee. Retrieved October 22, 2021, from

https://www.tilburguniversity.edu/research/social-and-behavioral-sciences/science-comm ittee

Tiokhin, L., Panchanathan, K., Lakens, D., Vazire, S., Morgan, T., \& Zollman, K. (2021). Honest signaling in academic publishing. PloS One, 16(2), e0246675.

Turchin, P. (2016). Ultrasociety: How 10,000 years of war made humans the greatest cooperators on earth. Beresta Books Chaplin, CT.

Van Noorden, R. (2014). Irish university labs face external audits. Nature News, 510(7505), 325. https://doi.org/10.1038/510325a

Vazire, S., \& Holcombe, A. O. (2020). Where Are The Self-Correcting Mechanisms In Science? PsyArXiv. https://doi.org/10.31234/osf.io/kgqzt

Vonnegut, K. (1997). Hocus pocus. Penguin.

Wade, M. J., Bijma, P., Ellen, E. D., \& Muir, W. (2010). Group selection and social evolution in domesticated animals. Evolutionary Applications, 3(5-6), 453-465. https://doi.org/10.1111/j.1752-4571.2010.00147.x

West, S. A., Fisher, R. M., Gardner, A., \& Kiers, E. T. (2015). Major evolutionary transitions in individuality. Proceedings of the National Academy of Sciences, 112(33), 10112-10119. https://doi.org/10.1073/pnas.1421402112

Woolley, A. W., Chabris, C. F., Pentland, A., Hashmi, N., \& Malone, T. W. (2010). Evidence for a Collective Intelligence Factor in the Performance of Human Groups. Science, 330(6004), 686-688. https://doi.org/10.1126/science.1193147

Wu, L., Wang, D., \& Evans, J. A. (2019). Large teams develop and small teams disrupt science and technology. Nature, 566(7744), 378-382.

Wuchty, S., Jones, B. F., \& Uzzi, B. (2007). The increasing dominance of teams in production of knowledge. Science, 316(5827), 1036-1039.

Zefferman, M. R., \& Mathew, S. (2015). An evolutionary theory of large-scale human warfare: 
Group-structured cultural selection. Evolutionary Anthropology: Issues, News, and Reviews, 24(2), 50-61. 